\title{
Alumina Support for Cobalt Catalyst in a Methane Dry Reforming Reaction: The Role of Water Content in a Solvent Medium
}

\author{
My Hien Thi Bach, ${ }^{1}$ Ngoc Thang Tran,, ${ }^{1}$ Thanh Nha Thi Tran, ${ }^{1}$ Van Cuong Nguyen $\mathbb{D}^{\mathbb{D}},{ }^{1}$ \\ and Hong Anh Thi Nguyen $\mathbb{1 D}^{2}$ \\ ${ }^{1}$ Faculty of Chemical Engineering, Industrial University of Ho Chi Minh City, 12 Nguyen Van Bao St, Go Vap, \\ Ho Chi Minh 70000, Vietnam \\ ${ }^{2}$ Faculty of Chemical Engineering, Ho Chi Minh City University of Food Industry, 140 Le Trong Tan St, \\ Ho Chi Minh 70000, Vietnam \\ Correspondence should be addressed to Hong Anh Thi Nguyen; anhnth@hufi.edu.vn
}

Received 14 November 2020; Revised 20 January 2021; Accepted 23 January 2021; Published 11 February 2021

Academic Editor: Eshorame Samuel Sanni

Copyright (c) 2021 My Hien Thi Bach et al. This is an open access article distributed under the Creative Commons Attribution License, which permits unrestricted use, distribution, and reproduction in any medium, provided the original work is properly cited.

\begin{abstract}
This study aimed to synthesize alumina from an inorganic aluminum nitrate precursor in various binary solvent systems of ethanol and water using the sol-gel self-assembly (SSA) method, employing a triblock copolymer, pluronic P123, as the poredirecting agent. The resulting materials were implemented as a support for the cobalt (Co) catalyst in a methane dry reforming (MDR) reaction at $1073 \mathrm{~K}$ under $1 \mathrm{~atm}$. Regardless of the water percentage used in the support synthesis, the methane dry reforming reaction over Co catalysts on alumina supports showed the negligible change in conversion during the $12 \mathrm{~h}$ reaction. Moreover, there was evidence of large quantities of amorphous carbon and graphitic carbon on the spent catalyst surface. However, the low oxidation temperature of these deposited carbons could help maintain the balance between the carbon formation and the carbon elimination processes on the catalyst surface during the reforming reaction, hence prolonging the lifetime of the catalyst. The high conversion of methane $\left(\mathrm{CH}_{4}\right)$ from $64.6 \%$ to $82.8 \%$ and carbon dioxide $\left(\mathrm{CO}_{2}\right)$ from $70.7 \%$ to $86.6 \%$ for the MDR reaction over the as-prepared alumina-supported Co catalyst demonstrated a significant improvement in catalyst production for the MDR reaction from the viewpoint of large-scale applications.
\end{abstract}

\section{Introduction}

The increase in the average temperature and climate change caused by greenhouse gases has become serious global issues. The human activities such as the burning of oil, coal, and gas, as well as deforestation, are associated with energy-related carbon dioxide $\left(\mathrm{CO}_{2}\right)$ emissions in the atmosphere. Therefore, in addition to the need to find new eco-energy sources, the use of mineral resources in an ecological and environmental approach is also a significant concern. Consequently, the methane dry reforming (MDR) method has emerged as a potential approach for producing syngas from $\mathrm{CO}_{2}$ and methane $\left(\mathrm{CH}_{4}\right)$, which is a significant feedstock for downstream petrochemical processes [1-6]. Although this approach could have environmental and economic benefits, the catalyst limitations have impeded it from wide-ranging applications in large-scale industrial production.

Noble metals, such as rhodium $(\mathrm{Rh})$, ruthenium $(\mathrm{Ru})$, and platinum $(\mathrm{Pt})$, have significant catalytic activity for the MDR process in terms of conversion and coking inhibition [7]. However, the unavailability and expensive cost of these catalysts are major drawbacks preventing their use in industrial applications. To date, cobalt- (Co-) based catalysts have garnered considerable attention since they possess comparable catalytic activity and higher stability against temperature variations in comparison to noble metals $[8,9]$. Moreover, different metal oxides have been evaluated as the support for a Co-catalyzed MDR reaction, such as oxides of the alkaline Earth elements, including magnesium oxide 
$(\mathrm{MgO})$, calcium oxide $(\mathrm{CaO})$ [8], ceric dioxide $\left(\mathrm{CeO}_{2}\right)$ [10], lanthanum dioxide $\left(\mathrm{LaO}_{2}\right)$ [11], strontium oxide $(\mathrm{SrO})$ [12], aluminum oxide $\left(\mathrm{Al}_{2} \mathrm{O}_{3}\right)$ [13-16], and Santa Barbara Amorphous-15 (SBA-15) [17-19]. Among of these materials, mesoporous alumina (MA) has been proven to be a potential support because of its availability. Recent contributions in heterogeneous catalysis regarding porous support and mesoporous structure materials have been widely used as catalyst supports since they can facilitate the dispersion of the catalysts and confine the active particles inside their matrix, preventing them from aggregating during the reaction [17, 19-21]. Mesoporous alumina support is one of the materials that has a high potential for being screened for the same effects in a MDR reaction.

Sol-gel self-assembly (SSA) is a common approach used for mesoporous $\mathrm{Al}_{2} \mathrm{O}_{3}$ production due to its easy, accessible, and reproducible characteristics in fabricating mesoporous structures [22]. Most SSA processes have been conducted by employing an organic salt precursor dispersed on a soft template dissolved in anhydrous ethanol $\left(\mathrm{C}_{2} \mathrm{H}_{5} \mathrm{OH}\right)[22,23]$. However, the toxicity and the high cost of organic salt and anhydrous $\left(\mathrm{C}_{2} \mathrm{H}_{5} \mathrm{OH}\right)$ ethanol have made them the most unlikely substances for this purpose. Thus, interest in using a less expensive and readily available inorganic aluminum precursor in large-scale applications is increasing. Additionally, the presence of water in the solvent has a significant influence on the pore structure of the resulting alumina materials [24], thus enabling intrapellet diffusion of the active nanoparticles in the porous framework [25]. To the best of our knowledge, only a few studies have investigated the combination of an inorganic aluminum precursor and a binary solvent mixture $\left(\mathrm{C}_{2} \mathrm{H}_{5} \mathrm{OH}\right.$ in $\left.\mathrm{H}_{2} \mathrm{O}\right)$ for synthesis of alumina using the SSA method, to act as a support for a Co catalyst in an MDR reaction. Therefore, instead of using an organic salt precursor and anhydrous ethanol, the present study employed a combination of an inorganic aluminum precursor and a binary solvent mixture $\left(\mathrm{C}_{2} \mathrm{H}_{5} \mathrm{OH}\right.$ in $\left.\mathrm{H}_{2} \mathrm{O}\right)$ for alumina synthesis using the SSA method. The performance of the Co catalyst on the as-prepared supports for the MDR reaction was evaluated to determine the amount of water needed in the solvent when preparing the support.

\section{Materials and Methods}

2.1. Chemicals. Aluminum nitrate $\mathrm{Al}\left(\mathrm{NO}_{3}\right)_{3} \cdot 9 \mathrm{H}_{2} \mathrm{O}(\geq 98 \%)$ and fuming hydrochloric acid $(\mathrm{HCl})(37 \%)$ were purchased from Merck (Darmstadt, Germany). Pluronic ${ }^{\circledR}$ P-123 $(\mathrm{MV}=5800)$ and cobalt (II) nitrate $\left(\mathrm{Co}\left(\mathrm{NO}_{3}\right)_{2} \cdot 6 \mathrm{H}_{2} \mathrm{O}, 98 \%\right)$ were obtained from Sigma-Aldrich (St. Louis, Missouri, US). $\mathrm{C}_{2} \mathrm{H}_{5} \mathrm{OH}(99.9 \%)$ was obtained from VWR Chemicals (Darmstadt, Germany). All the reagents were used directly without any further purification. All the gases, including $\mathrm{CH}_{4}, \mathrm{CO}_{2}$, nitrogen $\left(\mathrm{N}_{2}\right)$, and hydrogen $\left(\mathrm{H}_{2}\right)$, were of analytical grade and provided by Air Products and Chemicals, Inc.
2.2. Catalyst Synthesis. $\mathrm{Al}_{2} \mathrm{O}_{3}$ was prepared by dissolving $0.98 \mathrm{~g}$ of $\mathrm{P}-123$ in $14.6 \mathrm{ml}$ of the $\mathrm{C}_{2} \mathrm{H}_{5} \mathrm{OH}-\mathrm{H}_{2} \mathrm{O}$ solvent mixture with the following proportions of water: $0 \%, 25 \%$, $50 \%$, and $75 \%$. This solvent mixture was mixed at an ambient temperature for $30 \mathrm{~min}$, followed by adding $3.68 \mathrm{~g}$ of $\mathrm{Al}\left(\mathrm{NO}_{3}\right)_{3} \cdot 9 \mathrm{H}_{2} \mathrm{O}$ and dropping $1.6 \mathrm{ml} \mathrm{HCl}(37 \%)$ solution. The obtained blend was additionally stirred for $60 \mathrm{~min}$ prior to undergoing the hydrothermal process at $373 \mathrm{~K}$ for $24 \mathrm{~h}$ in an autoclave. The obtained mixture was dried in the oven for $48 \mathrm{~h}$ at $333 \mathrm{~K}$ and then calcined in a furnace for $5 \mathrm{~h}$ at $1073 \mathrm{~K}$.

The $\mathrm{Al}_{2} \mathrm{O}_{3}$-supported Co catalyst was prepared using the incipient wetness impregnation method. In particular, $0.28 \mathrm{~g}$ of the $\mathrm{Co}\left(\mathrm{NO}_{3}\right)_{2} \cdot 6 \mathrm{H}_{2} \mathrm{O}$ precursor was mixed with $0.25 \mathrm{ml}$ of $\mathrm{C}_{2} \mathrm{H}_{5} \mathrm{OH}$, and the resulting solution was sprayed on $0.5 \mathrm{~g}$ of as-synthesized alumina. The resulting mixture was dried overnight at $373 \mathrm{~K}$ and then calcined at $873 \mathrm{~K}$ for $5 \mathrm{~h}$. The individual alumina support, prepared from the binary solvent system with a water content of $0 \%, 25 \%, 50 \%$ and $75 \%$, was labelled as MA00, MA25, MA50, and MA75, respectively. Consequently, the supported Co catalysts synthesized from the abovementioned support were denoted as $10 \mathrm{Co} /$ MA00, 10Co/MA25, 10Co/MA50, and 10Co/MA75.

2.3. Catalyst Properties. The phases and crystalline structure of the selected spent catalysts were determined using a Rigaku Miniflex 600 X-ray diffraction instrument, which employed a copper $(\mathrm{Cu})$ target as the radiation source at the wavelength of $1.5418 \AA$. The test specimen was scanned from $3^{\circ}$ to $80^{\circ}$ with the speed of $1^{\circ} \mathrm{min}^{-1}$.

The amount of deposited carbons on the spent catalysts was quantified via the thermal programmed oxidation conducted on a TA TGA Q500 equipment (TA Instruments, Newcastle, DE, USA). In particular, the sample was heated at $373 \mathrm{~K}$ in $\mathrm{N}_{2}$ atmosphere for $30 \mathrm{~min}$ to eliminate the volatile compounds, followed by increasing the temperature to $1023 \mathrm{~K}$ in a mixture flow of $20 \% \mathrm{O}_{2}$ in $\mathrm{N}_{2}$ with a ramping rate of $10 \mathrm{~K} \mathrm{~min}^{-1}$. The oxidation stage at $1023 \mathrm{~K}$ was left for an additional $30 \mathrm{~min}$ prior to cooling to room temperature.

The surface morphology of the selected catalysts was elucidated using scanning electron microscope (SEM) equipped with an energy-dispersive X-ray (EDX) detector (Hitachi Tabletop Microscope TM3030 Plus unit, Hitachi High Technologies Corp., Tokyo, Japan) and a Raman spectrometer employing $532 \mathrm{~nm}$ laser excitation (JASCO NRS-3100, Tokyo, Japan).

2.4. Catalytic Activity Evaluation. The fixed-bed reactor with a 3/8 diameter was used to evaluate the MDR reaction catalyzed by the alumina-supported $\mathrm{Co}$ at a fixed gas hourly space velocity (GHSV) of $36 \mathrm{~L}_{\mathrm{c}} \mathrm{c}_{\mathrm{cat}}^{-1} \cdot \mathrm{h}^{-1}$. Prior to each assessment, $\mathrm{H}_{2}$ reduction was done in situ at $1073 \mathrm{~K}$ for $1 \mathrm{~h}$ using a mixed flow of $50 \% \mathrm{H}_{2}$ in $\mathrm{N}_{2}$. The output products were analyzed in an Agilent 6890 gas chromatography (Agilent Technologies, Santa Clara, CA, USA). The reactant conversions $\left(X_{i}\right.$ with $i: \mathrm{CH}_{4}$ and $\left.\mathrm{CO}_{2}\right)$ and product yields 
$\left(Y_{\mathrm{CO}}\right.$ and $Y_{\mathrm{H}_{2}}$ ) were estimated using the following equations, respectively:

$$
\begin{gathered}
X_{i}(\%)=\frac{F_{i}^{\text {in }}-F_{i}^{\text {out }}}{F_{i}^{\text {in }}} \times 100 \%, \\
Y_{\mathrm{CO}}(\%)=\frac{F_{\mathrm{CO}}^{\text {out }}}{\left(F_{\mathrm{CH}_{4}}^{\text {in }}+F_{\mathrm{CO}_{2}}^{\text {in }}\right)} \times 100 \%, \\
Y_{\mathrm{H}_{2}}(\%)=\frac{F_{\mathrm{H}_{2}}^{\text {out }}}{2 x F_{\mathrm{CH}_{4}}^{\text {in }}} \times 100 \%,
\end{gathered}
$$

where $F^{\text {in }}$ and $F^{\text {out }}$ are the inlet and outlet molar flow rates $\left(\mathrm{mol} \mathrm{s}^{-1}\right)$, respectively.

\section{Results and Discussion}

\subsection{Catalyst Assessment of the MDR Reaction}

3.1.1. Effect of Different Types of Alumina Support on the $M D R$ Reaction. Four substrates, prepared using a mixedsolvent of $\mathrm{C}_{2} \mathrm{H}_{5} \mathrm{OH}$ and different proportions of $\mathrm{H}_{2} \mathrm{O}(0 \%$, $25 \%, 50 \%$, or $75 \%$ ), were applied as a support for the Co catalyst, and the catalytic performance of the substrates for the MDR reaction was evaluated at a stoichiometric feed ratio and temperature of $1073 \mathrm{~K}$. As seen in Figures 1-4, the conversion of the reactants and the product yield were unchanged within the $12 \mathrm{~h}$ reaction, indicating the firm stability of the four catalysts under MDR reaction conditions. The conversion of $\mathrm{CO}_{2}$ and $\mathrm{CH}_{4}$ in the $\mathrm{MDR}$ reaction showed a decreasing trend from $86.6 \%$ to $70.7 \%$ and from $82.8 \%$ to $64.6 \%$, respectively, in the order of $10 \mathrm{Co} /$ MA00 > 10Co/MA25 > 10Co/MA50 > 10Co/MA75 catalysts. This decrease in catalyst performance along with an increase in the water concentration in the solvent for the support preparation could be due to the modification in the support's pore structure, which was caused by the increase in the water content. Thus, the MDR reaction performance strongly depends on the support's features and the active Co metal properties, such as crystal size and dispersion [26]. Furthermore, it has been reported that the percentage of water in the solvent mixture has a significant impact on enlarging the pore diameter of MA produced using the SSA method [23], hence facilitating the generation of active metals with an appropriate size and enhancing the intrapellet diffusion of both the reactants and the products [25].

The effectiveness of the MDR reaction was consolidated via the time on stream (TOS) plot of the $\mathrm{H}_{2}$ and $\mathrm{CO}$ formation yields, as seen in Figures 3 and 4. The support in catalyst activity was observed to play a significant role in both the $\mathrm{CO}$ and $\mathrm{H}_{2}$ yields. In particular, the $\mathrm{H}_{2}$ and $\mathrm{CO}$ yields were highest in the case of the $10 \% \mathrm{Co} / \mathrm{MA} 00$ catalyst; they were about $62.4-68.7 \%$ and $71.2-76.0 \%$, respectively. When the MDR reaction was conducted with the $10 \% \mathrm{Co} /$ MA75 catalyst, the $\mathrm{CO}$ yield decreased by approximately $10-20 \%$ and the $\mathrm{H}_{2}$ yield decreased by approximately $20-30 \%$. Regardless of the type of support, the $\mathrm{H}_{2} / \mathrm{CO}$ ratio was always $<1$, thus proving the coexistence of the reverse water-gas-shift process in the MDR reaction [27].
3.1.2. Effect of $\mathrm{CH}_{4}$ and $\mathrm{CO}_{2}$ Partial Pressure on the $\mathrm{MDR}$ Reaction. To evaluate the partial pressure influence of $\mathrm{CH}_{4}$ $\left(P_{\mathrm{CH}_{4}}\right)$ and $\mathrm{CO}_{2}\left(P_{\mathrm{CO}_{2}}\right)$ on $\mathrm{MDR}$, the reactions over the $10 \%$ Co/MA00 catalyst were conducted with $P_{\mathrm{CH}_{4}}$ and $P_{\mathrm{CO}_{2}}$ in the range of $10-40 \mathrm{kPa}$ at a temperature of $1023 \mathrm{~K}$. Figure 5 shows the correlation between the $\mathrm{CH}_{4}$ and $\mathrm{CO}_{2}$ conversions with the change in $P_{\mathrm{CH}_{4}}$ at $P_{\mathrm{CO}_{2}}$ of $20 \mathrm{kPa}$ (Figure 5(a)) and the change in $P_{\mathrm{CO}_{2}}$ at a fixed $P_{\mathrm{CH}_{4}}$ of $20 \mathrm{kPa}$ (Figure 5(b)). The $\mathrm{CH}_{4}$ conversion gradually decreased by approximately $15.0 \%$ as $P_{\mathrm{CH}_{4}}$ increased from $10 \mathrm{kPa}$ to $40 \mathrm{kPa}$ (see Figure 5(a)). This decrease in the $\mathrm{CH}_{4}$ conversion was due to the upsurge in carbon formation caused by extreme $\mathrm{CH}_{4}$ cracking in the surplus of the $\mathrm{CH}_{4}$ feedstock. The formed carbon induced active sites blocking and hindering the catalytic performance of the MDR reaction [28]. In contrast, the $\mathrm{CO}_{2}$ conversion increased and reached $80.6 \%$ when the $P_{\mathrm{CH}_{4}}$ increased from $10 \mathrm{kPa}$ to $40 \mathrm{kPa}$.

Thus, the increase in $P_{\mathrm{CH}_{4}}$ resulted in superior $\mathrm{CH}_{4}$ adsorption on the catalyst, therefore improving the $\mathrm{CO}_{2}$ consumption through the MDR reaction [29]. A similar trend was also observed for the MDR reaction over the $\mathrm{CeO}_{2}$-supported Co catalyst [28].

However, the $\mathrm{CH}_{4}$ conversion showed continuous improvement to $82.7 \%$ when $P_{\mathrm{CO}_{2}}$ increased from $10 \mathrm{kPa}$ to $40 \mathrm{kPa}$, while $P_{\mathrm{CH}_{4}}$ was kept at $20 \mathrm{kPa}$ (see Figure 5(b)). This behaviour can be linked to the enhanced elimination of the deposited carbon, as depicted in equation (4) [30], and the coinciding existence of the $\mathrm{CH}_{4}$ steam reforming process that was due to the increase in $\mathrm{H}_{2} \mathrm{O}$ via the reverse water-gasshift process, as follows [31]:

$$
\begin{gathered}
\mathrm{CH}_{4} \underset{-\mathrm{H}_{2}}{\longrightarrow} \mathrm{C}_{x} \mathrm{H}_{1-x} \underset{+\mathrm{CO}_{2}}{\longrightarrow} \mathrm{H}_{2}+\mathrm{CO} \\
\mathrm{CO}_{2}+\mathrm{H}_{2} \leftrightarrow \mathrm{CO}+\mathrm{H}_{2} \mathrm{O}
\end{gathered}
$$

A decrease in the $\mathrm{CO}_{2}$ conversion was found when $P_{\mathrm{CO}_{2}}$ increased from $10 \mathrm{kPa}$ to $40 \mathrm{kPa}$ (see Figure 5(b)), which could be due to the deficiency of $\mathrm{CH}_{4}$ in reacting with the $\mathrm{CO}_{2}$-rich feedstock. Furthermore, the presence of excess $\mathrm{CO}_{2}$ in the reactor could intensify the possibility for active Co particles to be oxidized as follows, which resulted in a decrease in $\mathrm{CO}_{2}$ adsorption [27]:

$$
3 \mathrm{Co}+4 \mathrm{CO}_{2} \longrightarrow \mathrm{Co}_{3} \mathrm{O}_{4}+4 \mathrm{CO}
$$

\subsection{Characterization of the Spent Catalyst}

3.2.1. XRD Analysis. The XRD spectrum of the synthesized $10 \% \mathrm{Co} / \mathrm{MA} 00$ after $12 \mathrm{~h} \mathrm{MDR}$ reaction at $1073 \mathrm{~K}$ is shown in Figure 6. The peaks at $2 \theta$ of $37.6^{\circ}, 45.6^{\circ}$, and $67.0^{\circ}$ were assigned to the $\mathrm{Al}_{2} \mathrm{O}_{3}$ phase (JCPDS card no. 04-0858); the signals at $31.7^{\circ}, 37.5^{\circ}$, and $44.6^{\circ}$ corresponded to the $\mathrm{Co}_{3} \mathrm{O}_{4}$ crystalline phase (JCPDS card no. 74-2120). Moreover, the metallic Co presence was verified via the detection of a peak at $51.6^{\circ}$ (JCPDS card no. 15-0806). The copresence of Co metallic and oxide particles in the $10 \% \mathrm{Co} / \mathrm{MA} 00$ sample indicated the occurrence of the redox cycle of the Co species during the MDR reaction. Notably, a broad peak at $2 \theta$ from 


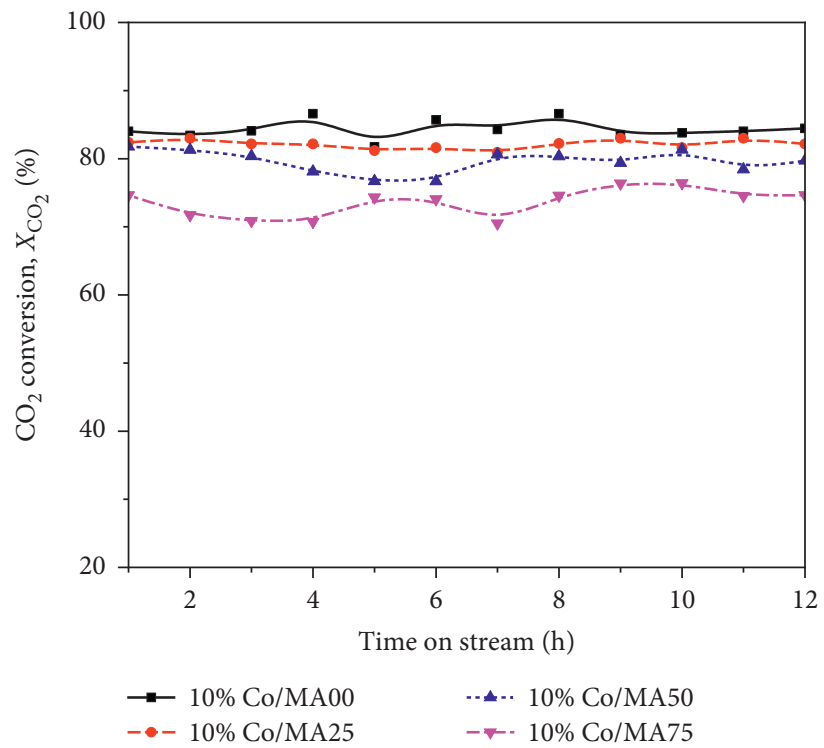

FIgURE 1: Time on stream conversion of $\mathrm{CO}_{2}$ in $\mathrm{MDR}$ over different catalysts at $1073 \mathrm{~K}$.

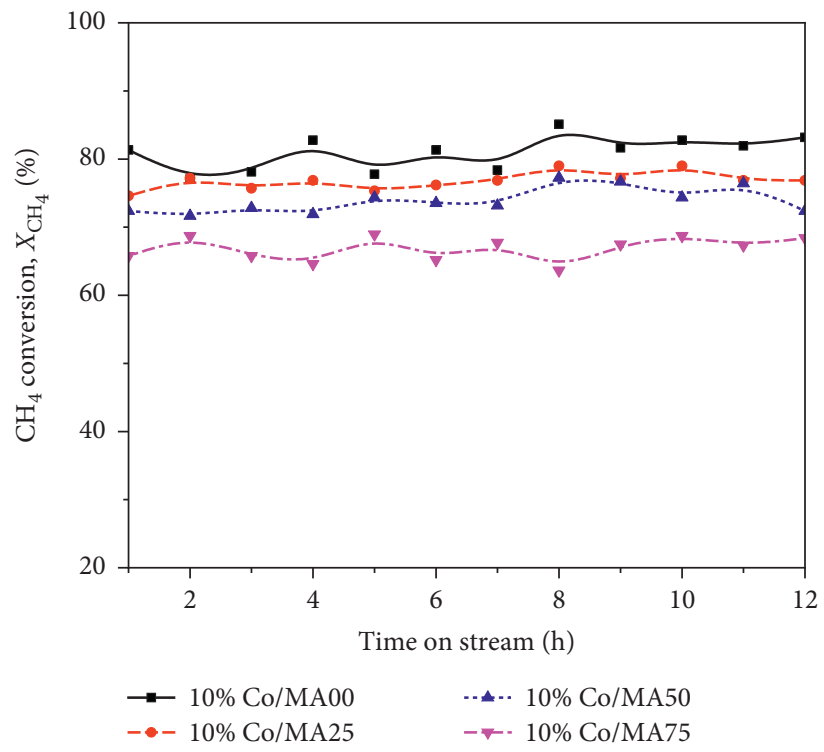

FIgURE 2: Time on stream conversion of $\mathrm{CH}_{4}$ in MDR over different catalysts at $1073 \mathrm{~K}$.

$15.0^{\circ}$ to $30.0^{\circ}$ was deconvoluted into two separate diffraction signals, denoted as $\alpha$ and $\beta$, and displayed in a small inserted picture in Figure 6. The $\alpha$ peak represents amorphous carbon, and the $\beta$ peak represents graphitic carbon [32].

\subsubsection{Raman Measurements. Figure 7 shows the Raman} spectrum of the $10 \% \mathrm{Co} / \mathrm{MA} 00$ after $12 \mathrm{~h}$ MDR reaction at $1073 \mathrm{~K}$. Four active Raman peaks at $473.9 \mathrm{~cm}^{-1}, 517.7 \mathrm{~cm}^{-1}$, $609.7 \mathrm{~cm}^{-1}$, and $678.5 \mathrm{~cm}^{-1}$, illustrated in the embedded picture, were assigned to the corresponding $\mathrm{Co}_{3} \mathrm{O}_{4}$ symmetric vibrational modes of $\mathrm{E}_{\mathrm{g}}, \mathrm{F}_{2 \mathrm{~g}}, \mathrm{~F}_{2 \mathrm{~g}}$, and $\mathrm{A}_{1 \mathrm{~g}}$. The signal at $678.5 \mathrm{~cm}^{-1}$ represents the vibration of the octahedral site, and the $E_{g}$ and $F_{2 g}$ modes are likely related to the mixed vibrations of the octahedral site and the tetrahedral oxygen movements [33]. These typical peaks were observed in the Raman spectra of the spent catalyst, suggesting that the reduced $\mathrm{Co}^{0}$ species in the $\mathrm{H}_{2}$ pretreatment were reoxidized to $\mathrm{Co}_{3} \mathrm{O}_{4}$ during the $\mathrm{MDR}$ reaction. Two peaks at $1338.5 \mathrm{~cm}^{-1}$ and $1573.5 \mathrm{~cm}^{-1}$ demonstrate the heterogeneity of the surface carbons including ordered carbon-like graphite (G-band) and amorphous carbon (D-band). The D-band was attributed to amorphous carbon or carbon nanofibers, while the G-band arises from the stretching of the C-C bond in graphitic carbon [34].

3.2.3. Surface Morphology Analyses. The SEM-EDX measurements of the $10 \% \mathrm{Co} / \mathrm{MA} 00$ catalyst after MDR at $1073 \mathrm{~K}$ suggest the presence of filamentous carbons or 


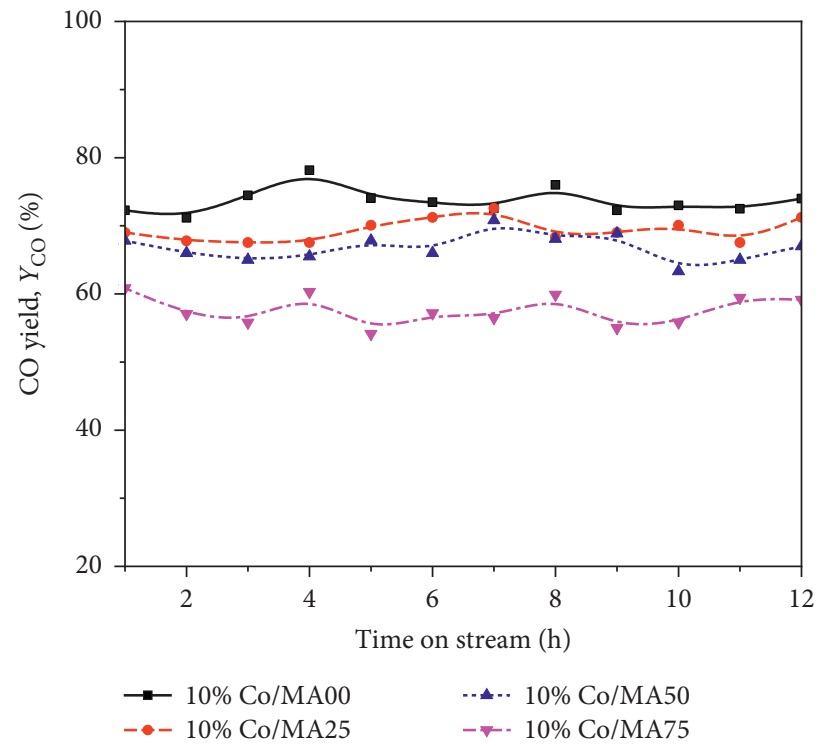

Figure 3: Time on stream yield of CO in MDR over different catalysts at $1073 \mathrm{~K}$.

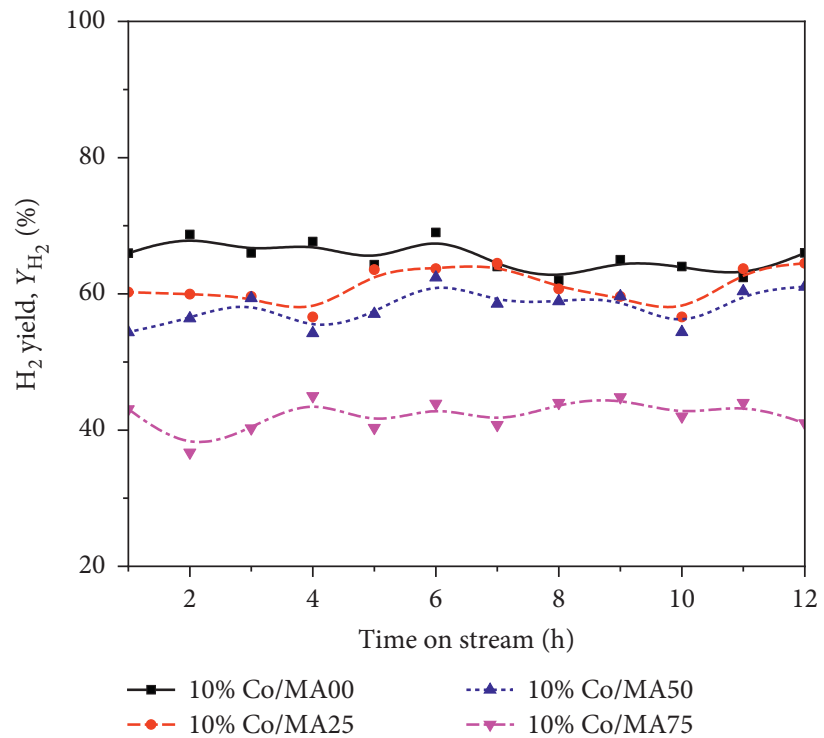

Figure 4: Time on stream yield of $\mathrm{H}_{2}$ in MDR over different catalysts at $1073 \mathrm{~K}$.

carbon fibers, as shown in Figure 8. The percentage of total carbon in the catalyst was around $64.03 \%$ based on the normalized EDX results. This could be due to the fact that the alumina-supported Co catalyst is known to boost the formation of filamentous carbon in a $\mathrm{CH}_{4}$ atmosphere at high temperature [35].

3.2.4. TPO Measurements. Thermal-programmed oxidation (TPO) was performed to quantify the sum of the carbon deposits on the $10 \%$ Co/MA00 catalyst after MDR at $1073 \mathrm{~K}$. As seen in Figure 9, about 77.1\% weight of the sample was lost after the oxidation at temperatures ranging from $700 \mathrm{~K}$ to $850 \mathrm{~K}$, which is in agreement with the EDX results (see Table 1). The differences in the results obtained from the two analytical methods could be due to the decomposition of the other elements in the TPO measurement.

Moreover, the low oxidation temperature of the deposited carbon at temperatures ranging from $750 \mathrm{~K}$ to $820 \mathrm{~K}$, as determined from the derivative weight curves, suggest that all the deposits were well gasified in the reforming conditions; hence, they did not cause a loss of intrinsic catalyst activity or lengthen the lifetime of the catalyst [13]. 


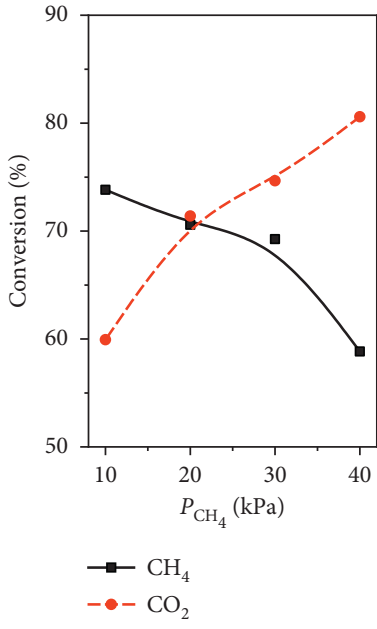

(a)

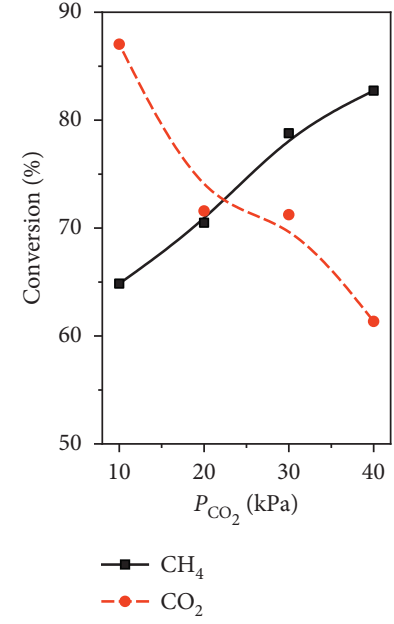

(b)

FIgURE 5: Influence of $P_{\mathrm{CH}_{4}}$ and $P_{\mathrm{CO}_{2}}$ on the $\mathrm{CH}_{4}$ and $\mathrm{CO}_{2}$ conversions in MDR over $10 \% \mathrm{Co} / \mathrm{MA} 00$ at $1023 \mathrm{~K}$.

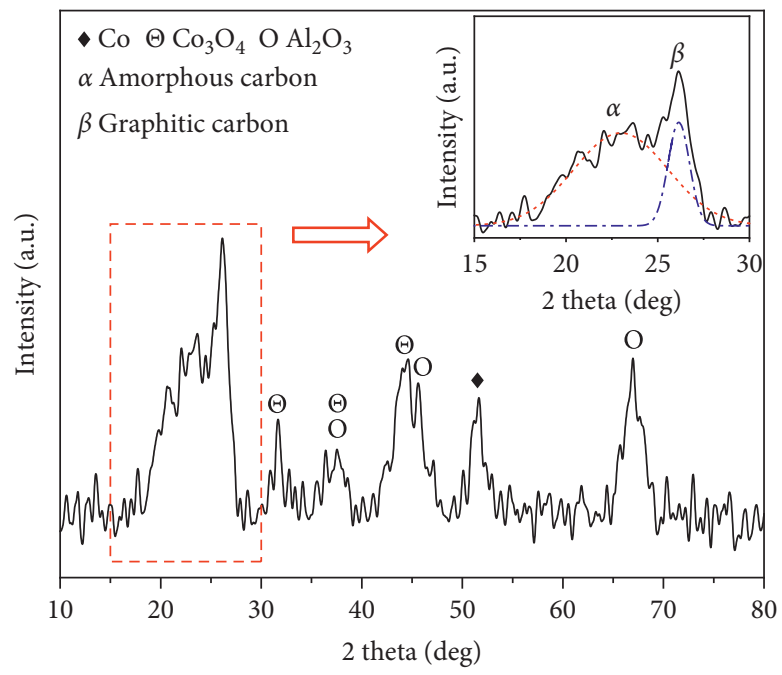

FIgURE 6: XRD spectra of spent 10\% Co/MA00 after MDR at a stoichiometric feed ratio of 1 and $1073 \mathrm{~K}$.

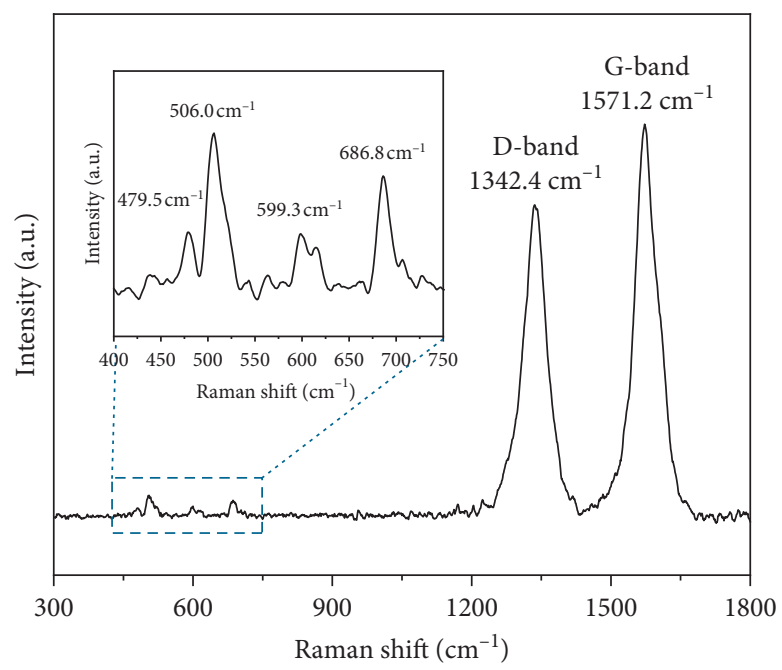

FIGURE 7: Raman spectra of the spent 10\% Co/MA00 after MDR at $1073 \mathrm{~K}$ and stoichiometric feed ratio of 1. 


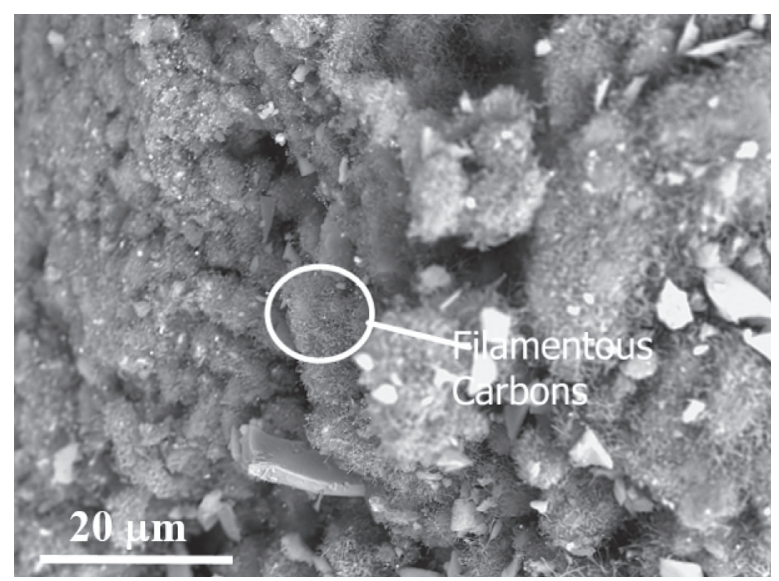

(a)

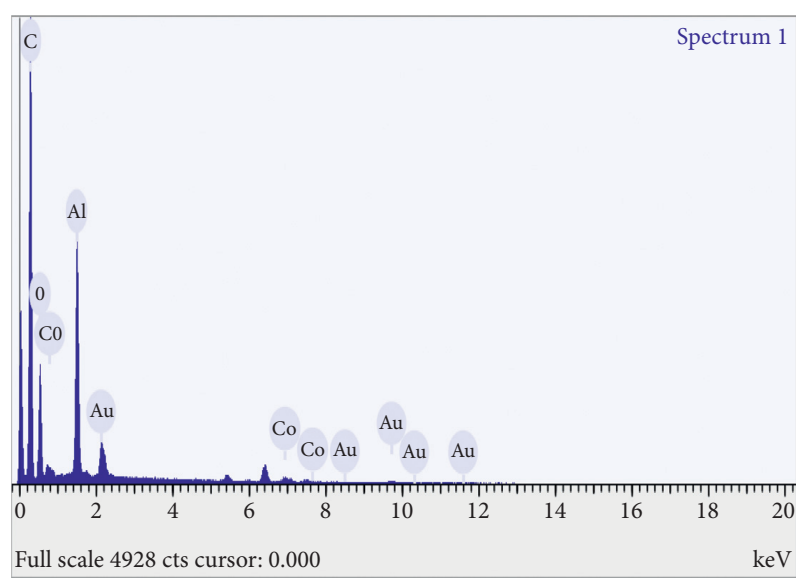

(b)

Figure 8: (a) SEM image and (b) EDX analysis of the $10 \% \mathrm{Co} / \mathrm{MA} 00$ catalyst after MDR at $1073 \mathrm{~K}$ and a stoichiometric feed ratio of 1.

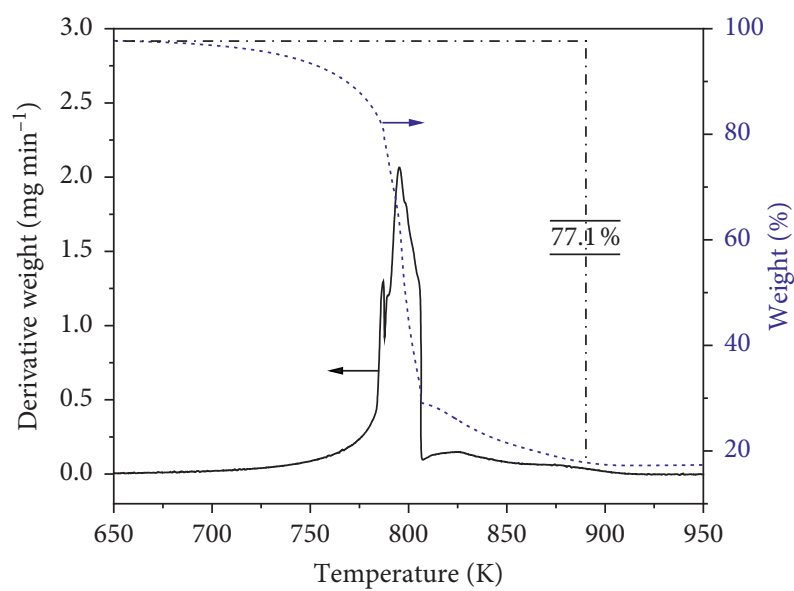

FIGURE 9: The weight loss and the derivative of weight loss profile of the $10 \% \mathrm{Co} / \mathrm{MA} 00$ catalyst after MDR at $1073 \mathrm{~K}$ and stoichiometric feed ratio of 1 .

TABLE 1: EDX measurement of the $10 \% \mathrm{Co} / \mathrm{MA} 00$ catalyst after MDR at $1073 \mathrm{~K}$.

\begin{tabular}{lc}
\hline Element & Weight (\%) \\
\hline Carbon (C) & 64.03 \\
Oxygen (O) & 27.81 \\
Aluminum (Al) & 7.30 \\
Cobalt (Co) & 0.86 \\
\hline
\end{tabular}

\section{Conclusions}

The performance of the Co catalysts supported on MA for the MDR reaction was investigated in terms of the support contribution. The water content in the solvent mixture applied for the $\mathrm{Al}_{2} \mathrm{O}_{3}$ support synthesis plays a crucial role in assembling the structure; hence, it influences the catalytic activity in the MDR reaction. Regardless of the type of support used, the Co catalysts showed good stability under $12 \mathrm{~h}$ MDR reaction. Notably, the $10 \% \mathrm{Co} / \mathrm{MA} 00$ catalyst demonstrated the highest activity for the MDR reaction with a carbon monoxide yield of $71.2-76.0 \%$, and the deposit on the spent $10 \% \mathrm{Co} / \mathrm{MA} 00$ catalyst surface was found to consist of both amorphous carbon and graphitic carbon possessing low-oxidation temperature property and hence easily be eliminated in situ the reaction process. Moreover, the reactant partial pressure was found to have a significant impact on the $\mathrm{CO}_{2}$ and $\mathrm{CH}_{4}$ conversions as well as the product yields when the MDR reaction was conducted at $1023 \mathrm{~K}$.

\section{Data Availability}

All experimental data used to support the findings of this study are available within the article.

\section{Conflicts of Interest}

The authors declare that they have no conflicts of interest.

\section{Acknowledgments}

The research was supported by the Industrial University of Ho Chi Minh City (no. 171.4081). 


\section{References}

[1] O. R. Inderwildi, S. J. Jenkins, and D. A. King, "Mechanistic studies of hydrocarbon combustion and synthesis on noble metals," Angewandte Chemie International Edition, vol. 47, no. 28, pp. 5253-5255, 2008.

[2] L. Kapokova, S. Pavlova, R. Bunina et al., "Dry reforming of methane over $\mathrm{LnFe}_{0.7} \mathrm{Ni}_{0.3} \mathrm{O}_{3-\delta}$ perovskites: influence of $\mathrm{Ln}$ nature," Catalysis Today, vol. 164, no. 1, pp. 227-233, 2011.

[3] M. Bradford and M. A. Vannice, " $\mathrm{CO}_{2}$ reforming of $\mathrm{CH}_{4}$," Catalysis Reviews, vol. 41, no. 1, pp. 1-42, 2007.

[4] M. Usman, W. M. A. Wan Daud, and H. F. Abbas, "Dry reforming of methane: influence of process parameters-a review," Renewable and Sustainable Energy Reviews, vol. 45, pp. 710-744, 2015.

[5] B. Abdullah, N. A. Abd Ghani, and D.-V. N. Vo, "Recent advances in dry reforming of methane over Ni-based catalysts," Journal of Cleaner Production, vol. 162, pp. 170-185, 2017.

[6] D.-V. N. Vo, T.-H. Nguyen, E. M. Kennedy, B. Z. Dlugogorski, and A. A. Adesina, "Fischer-Tropsch synthesis: effect of promoter type on alumina-supported Mo carbide catalysts," Catalysis Today, vol. 175, no. 1, pp. 450-459, 2011.

[7] S. Y. Foo, C. K. Cheng, T.-H. Nguyen, and A. A. Adesina, "Oxidative $\mathrm{CO}_{2}$ reforming of methane on alumina-supported Co-Ni catalyst," Industrial \& Engineering Chemistry Research, vol. 49, no. 21, pp. 10450-10458, 2010.

[8] E. Ruckenstein and H. Y. Wang, "Carbon dioxide reforming of methane to synthesis gas over supported cobalt catalysts," Applied Catalysis A: General, vol. 204, no. 2, pp. 257-263, 2000.

[9] A. W. Budiman, S.-H. Song, T.-S. Chang, C.-H. Shin, and M.-J. Choi, "Dry reforming of methane over cobalt catalysts: a literature review of catalyst development," Catalysis Surveys from Asia, vol. 16, no. 4, pp. 183-197, 2012.

[10] B. V. Ayodele, M. R. Khan, and C. K. Cheng, "Catalytic performance of ceria-supported cobalt catalyst for CO-rich hydrogen production from dry reforming of methane," International Journal of Hydrogen Energy, vol. 41, no. 1, pp. 198-207, 2016.

[11] B. V. Ayodele, M. R. Khan, S. S. Lam, and C. K. Cheng, "Production of CO-rich hydrogen from methane dry reforming over lanthania-supported cobalt catalyst: kinetic and mechanistic studies," International Journal of Hydrogen Energy, vol. 41, no. 8, pp. 4603-4615, 2016.

[12] K. Omata, N. Nukui, T. Hottai, Y. Showa, and M. Yamada, "Strontium carbonate supported cobalt catalyst for dry reforming of methane under pressure," Catalysis Communications, vol. 5, no. 12, pp. 755-758, 2004.

[13] É. Horváth, K. Baán, E. Varga et al., "Dry reforming of $\mathrm{CH}_{4}$ on $\mathrm{Co} / \mathrm{Al}_{2} \mathrm{O}_{3}$ catalysts reduced at different temperatures," $\mathrm{Ca}$ talysis Today, vol. 281, pp. 233-240, 2017.

[14] S. Zeng, L. Zhang, X. Zhang, Y. Wang, H. Pan, and H. Su, "Modification effect of natural mixed rare earths on $\mathrm{Co} /$ $\gamma-\mathrm{Al}_{2} \mathrm{O}_{3}$ catalysts for $\mathrm{CH}_{4} / \mathrm{CO}_{2}$ reforming to synthesis gas," International Journal of Hydrogen Energy, vol. 37, no. 13, pp. 9994-10001, 2012.

[15] D. San-José-Alonso, J. Juan-Juan, M. J. Illán-Gómez, and M. C. Román-Martínez, "Ni, Co and bimetallic Ni-Co catalysts for the dry reforming of methane," Applied Catalysis A: General, vol. 371, no. 1-2, pp. 54-59, 2009.

[16] D. San José-Alonso, M. J. Illán-Gómez, and M. C. RománMartínez, "Low metal content Co and Ni alumina supported catalysts for the $\mathrm{CO}_{2}$ reforming of methane," International Journal of Hydrogen Energy, vol. 38, no. 5, pp. 2230-2239, 2013.

[17] J. Xin, H. Cui, Z. Cheng, and Z. Zhou, "Bimetallic Ni-Co/SBA15 catalysts prepared by urea co-precipitation for dry reforming of methane," Applied Catalysis A: General, vol. 554, pp. 95-104, 2018.

[18] B. Erdogan, H. Arbag, and N. Yasyerli, "SBA-15 supported mesoporous $\mathrm{Ni}$ and Co catalysts with high coke resistance for dry reforming of methane," International Journal of Hydrogen Energy, vol. 43, no. 3, pp. 1396-1405, 2018.

[19] Z. Taherian, M. Yousefpour, M. Tajally, and B. Khoshandam, "Catalytic performance of Samaria-promoted $\mathrm{Ni}$ and $\mathrm{Co} /$ SBA-15 catalysts for dry reforming of methane," International Journal of Hydrogen Energy, vol. 42, no. 39, pp. 24811-24822, 2017.

[20] Q. Ma, J. Sun, X. Gao et al., "Ordered mesoporous aluminasupported bimetallic Pd-Ni catalysts for methane dry reforming reaction," Catalysis Science \& Technology, vol. 6, no. 17, pp. 6542-6550, 2016.

[21] S. Singh, R. Kumar, H. D. Setiabudi, S. Nanda, and D.-V. N. Vo, "Advanced synthesis strategies of mesoporous SBA-15 supported catalysts for catalytic reforming applications: a state-of-the-art review," Applied Catalysis A: General, vol. 559, pp. 57-74, 2018.

[22] Q. Yuan, A.-X. Yin, C. Luo et al., "Facile synthesis for ordered mesoporous $\gamma$-aluminas with high thermal stability," Journal of the American Chemical Society, vol. 130, no. 11, pp. 3465-3472, 2008.

[23] W. Wu, Z. Wan, W. Chen, M. Zhu, and D. Zhang, "Synthesis of mesoporous alumina with tunable structural properties," Microporous and Mesoporous Materials, vol. 217, no. 15, pp. 12-20, 2015.

[24] W. Wu, M. Zhu, and D. Zhang, "The role of solvent preparation in soft template assisted synthesis of mesoporous alumina," Microporous and Mesoporous Materials, vol. 260, pp. 9-16, 2018.

[25] K. Tao, Y. Zhang, S. Terao et al., "Chemical and spatial promotional effects of bimodal pore catalysts for methane dry reforming," Chemical Engineering Journal, vol. 170, no. 1, pp. 258-263, 2011.

[26] A. L. M. Da Silva, J. P. Den Breejen, L. V. Mattos, J. H. Bitter, K. P. de Jong, and F. B. Noronha, "Cobalt particle size effects on catalytic performance for ethanol steam reforming-smaller is better," Journal of Catalysis, vol. 318, pp. 67-74, 2014.

[27] O. Omoregbe, H. T. Danh, C. Nguyen-Huy et al., "Syngas production from methane dry reforming over Ni/SBA-15 catalyst: effect of operating parameters," International Journal of Hydrogen Energy, vol. 42, no. 16, pp. 11283-11294, 2017.

[28] B. V. Ayodele, M. R. Khan, and C. K. Cheng, "Syngas production from $\mathrm{CO}_{2}$ reforming of methane over ceria supported cobalt catalyst: effects of reactants partial pressure," Journal of Natural Gas Science and Engineering, vol. 27, pp. 1016-1023, 2015.

[29] M. A. Naeem, A. S. Al-Fatesh, W. U. Khan, A. E. Abasaeed, and A. H. Fakeeha, "Syngas production from dry reforming of methane over nano Ni polyol catalysts," International Journal of Chemical Engineering and Applications, vol. 4, no. 5, pp. 315-320, 2013.

[30] S. Y. Foo, C. K. Cheng, T. H. Nguyen, and A. A. Adesina, "Evaluation of lanthanide-group promoters on $\mathrm{Co}-\mathrm{Ni} / \mathrm{Al}_{2} \mathrm{O}_{3}$ catalysts for $\mathrm{CH}_{4}$ dry reforming," Journal of Molecular $\mathrm{Ca}$ talysis A: Chemical, vol. 344, no. 1-2, pp. 28-36, 2011. 
[31] A. Donazzi, A. Beretta, G. Groppi, and P. Forzatti, "Catalytic partial oxidation of methane over a $4 \% \mathrm{Rh} / \alpha-\mathrm{Al}_{2} \mathrm{O}_{3}$ catalyst part II: role of $\mathrm{CO}_{2}$ reforming," Journal of Catalysis, vol. 255, no. 2 , pp. $259-268,2008$.

[32] G. G. Tibbetts, G. L. Doll, D. W. Gorkiewicz et al., "Physical properties of vapor-grown carbon fibers," Carbon, vol. 31, no. 7, pp. 1039-1047, 1993

[33] A. Diallo, A. C. Beye, T. B. Doyle, E. Park, and M. Maaza, "Green synthesis of $\mathrm{Co}_{3} \mathrm{O}_{4}$ nanoparticles via Aspalathus linearis: physical properties," Green Chemistry Letters and Reviews, vol. 8, no. 3-4, pp. 30-36, 2015.

[34] W.-W. Liu, S.-P. Chai, A. R. Mohamed, and U. Hashim, "Synthesis and characterization of graphene and carbon nanotubes: a review on the past and recent developments," Journal of Industrial and Engineering Chemistry, vol. 20, no. 4, pp. 1171-1185, 2014.

[35] F. Frusteri, G. Italiano, C. Espro, and F. Arena, " $\mathrm{CH}_{4}$ decomposition on $\mathrm{Ni}$ and Co thin layer catalysts to produce $\mathrm{H}_{2}$ for fuel cell," Catalysis Today, vol. 171, no. 1, pp. 60-66, 2011. 